\title{
Fallacies of Risk Control
}

\author{
Jürgen Vandenbroucke ${ }^{1,2}$ \\ ${ }^{1}$ University of Antwerp, Antwerp, Belgium \\ ${ }^{2}$ KBC Asset Management NV, Brussels, Belgium \\ Correspondence: jurgenvandenbroucke@ hotmail.com \\ Disclaimer: The views expressed in this article do not necessarily coincide with the views of KBC Asset Management \\ $\mathrm{NV}$ or any other member of KBC Group.
}

Received: January 17, 2015

doi:10.11114/aef.v2i2.716
Accepted: February 13, 2015

Available online: March 12, 2015

URL: http://dx.doi.org/10.11114/aef.v2i2.716

\begin{abstract}
This paper demonstrates how risk control as applied to popular investment products can be based on a fallacy. In scope are option-based capital protected products and rules-based portfolio insurance products. In case of structured products risk control shifts the option's volatility risk from the product provider to the end investor. The investor is presented a different product, for better or for worse, and not an improved version of the "base" product. Adding risk control to the risky asset of portfolio insurance leaves the portfolio allocation unchanged if, for good reasons, market exposure is already inversely linked to volatility. The investor receives nothing else but the "base" product, be it in a commercially more appealing presentation.
\end{abstract}

\section{JEL Classification: G11, G23}

Keywords: risk control, volatility, structured products, portfolio insurance

\section{Introduction}

The recent financial crises have made institutional and private investors more risk aware. Portfolio management techniques that remedy excessive fluctuations in portfolio value gain popularity. The current paper focuses on volatility targeting or risk control, which is a popular member of the risk awareness family.

Portfolios that use the technique of risk control adjust market exposure inversely proportional to market volatility. As such, risk control has an intuitive interpretation. Market exposure is increased if volatility is low, while market exposure is build down if the magnitude of market fluctuations increases. Many financial product providers draw the card of risk control to address the growing risk awareness of investors. The sales stories of such financial products emphasize the application of risk control, and often claim an improved balance between risk and return.

The paper argues that risk control as applied to many popular investment products sold to retail is based on a fallacy. The focus is on option-based structured products and rules-based portfolio insurance products. In case of structured products, the use of risk control crucially alters the exposure of the end investor. A structured product that applies risk control is not just simply an improved version of a non-risk controlled counterpart. One is not a priori better or worse than the other, but it requires an investor view on future realized volatility versus current implied volatility to motivate the investment decision. Most retail investors are unaware. In case of portfolio insurance, the use of risk control merely changes the way of presenting the same product. The portfolio composition is not impacted by the use of risk control. What is impacted is the commercial potential, by touching the sensitive string of risk awareness.

The paper is organized as follows. A first section highlights the main features of volatility targeting. Section 2 illustrates how risk control fits option-based capital protected products. Section 3 covers rules-based portfolio insurance products. A final section summarizes the core arguments.

\section{Risk Control}

Investment decisions taken by a portfolio manager should comply with the investment policy. Such investment policy may specify that the portfolio will target a predefined level of volatility. The availability of risk controlled versions of established equity indices such as Standard and Poor's 500 (S\&P500 hereafter) supports a widespread use. Standard and Poor's (2015) gives a detailed description of the methodology underlying the calculation of the risk control indices. 
The general idea of risk control is to frequently adjust the portfolios' market exposure in order to match the volatility target. If for example the volatility target is set at $15 \%$ at a time the market exhibits a volatility of $20 \%$, the portfolio manager can only sustain $15 \% / 20 \%=75 \%$ market exposure. Formally:

$$
w_{t}=\frac{V}{\sigma_{t}}
$$

with $V$ the volatility target, $\sigma_{t}$ the prevailing market volatility of the invested assets at time $t$ and $w_{t}$ the resulting proportion of these assets in the portfolio. The complement $1-w_{t}$ is invested in a reserve asset with zero volatility, for example cash.

An alternative is to define a reserve asset with a low but non-zero volatility. The portfolio weight of both components is then obtained by solving the quadratic equation of portfolio volatility in order to comply with the volatility target. In general:

$$
V=\left[w_{t}^{2} \sigma_{t, 1}^{2}+\left(1-w_{t}\right)^{2} \sigma_{t, 2}^{2}+2 \rho_{t} \sigma_{t, 1} \sigma_{t, 2} w_{t}\left(1-w_{t}\right)\right]^{1 / 2}
$$

with $\sigma_{t, 1}$ and $\sigma_{t, 2}$ the prevailing market volatility of both invested assets, $\rho_{t}$ their correlation and $w_{t}$ the proportion invested in asset 1 . The complement $1-\mathrm{w}_{\mathrm{t}}$ is invested in asset 2 .

Figure 1 shows the available history of the S\&P500 Risk Control total return indices with cash as the reserve asset and a volatility target of $10 \%$ or $15 \%$, as well as the S\&P500 total return.

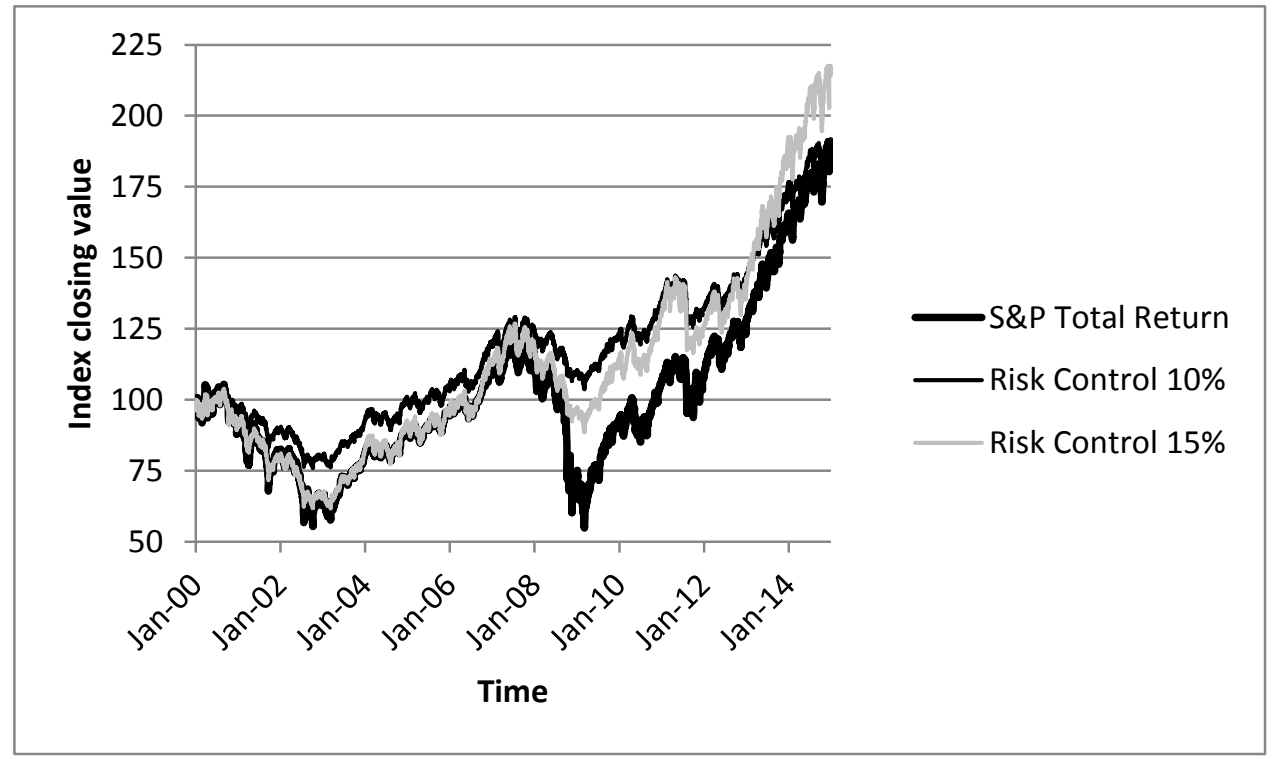

Figure 1. Historic evolution of S\&P500 and two Risk Control Indices.

Source: Bloomberg Finance L. P.

As volatility typically increases following a market downturn, the risk control indices reduce market exposure to prevent immediate further harm. Consider the last quarter of 2008 in figure 1 as an example. Market exposure is restored if volatility again decreases, which on average occurs once the market confirms a cycle of positive returns. In this respect the recent past has been beneficial for risk control strategies. During the '90s equity markets reported high returns with low volatility while the decade shown in figure 1 reported relatively poor returns with high volatilities. The last few years' volatility has decreased in combination with positive returns, which is clearly illustrated by the end of the series in figure 1.

\section{Option-Based Capital Protection}

Data sources such as www.StructuredRetailProducts.com confirm the widespread use of risk control in option-based structured products sold to retail.

The textbook example of an option-based capital protected product combines a zero-bond and a long call position. Both the bond and the option expire on the maturity date of the structured product. The terms and conditions are determined by the market conditions at start date and depend on the balance between the interest foregone by the investor, in exchange for the option, and the option premium. 
If interest rates are high and options come cheap, the investor enjoys capital protection at maturity and likely over $100 \%$ participation in the increase of the asset underlying the option. If interest rates are low and/or options are expensive, the same capital protection comes at the expense of only a minor participation in the increase of the underlying asset. The latter scenario describes the current market situation better than the former.

Consider the following stylized yet realistic example. Assume a structured product with capital protection at the end of a 5 year tenor with the payoff on top of the initial capital depending on the performance of S\&P500. The 5 year continuous interest rate is observed at $1.65 \%$ which means $1-\mathrm{e}^{-5 * 0.0165}=7.92 \%$ is available to buy options. The remainder, i.e. $92.08 \%$ of the inlay, is invested in 5 year zero bonds that restore the initial capital at maturity (ignoring fees). Investment banks quote a 5 year at-the-money European call at a price of $16.35 \%$ based on a volatility of $22.25 \%$, a dividend yield of $2.3 \%$ and using a standard option pricing model, see for example Hull (1989). Spending 7.92\% on options valued at $16.35 \%$ gives rise to a 5 year capital protected product with a payoff equal to $7.92 \% / 16.35 \%=48.44 \%$ of the increase in S\&P500 observed at maturity. The investor is protected against in case S\&P500 reports a negative performance over the 5 year investment horizon.

A product provider can try to cheapen the option in order to improve the commercial appeal of the structured product. Given that $7.92 \%$ of the investment is available to buy options, more than $48.44 \%$ of options can be bought if they cost less than $16.35 \%$. One possibility is to address at the same time the growing risk awareness and replace S\&P500 by a risk controlled version as the underlying value.

To see how the risk controlled underlying impacts the option price, consider a modeling approach along the lines of Black \& Scholes (1973). The evolution of the underlying asset $\mathrm{S}$ is described as a geometric Brownian motion:

$$
d S_{t}=S_{t}(r-q) d t+S_{t} \sigma_{t} d \varepsilon_{t}
$$

with $r$ the riskless rate, $q$ the dividend yield and $\sigma_{t}$ the volatility, possibly modeled as time-varying. The term $d \varepsilon_{t}$ represents the Brownian motion and $\varepsilon$ draws independent values from a standard normal distribution.

From this asset $S$ we derive the risk controlled variant $I$ as:

$$
I_{t}=I_{t-1}\left[1+P_{t-1}\left(\frac{s_{t}}{s_{t-1}}-1\right)\right]
$$

where $P_{t-1}=V / H_{t-1}$ with $V$ the fixed volatility target and $H$ the agreed volatility measure. Equation (4) assumes the participation $P$ is not limited on the upside or the downside. Without loss of generality the reserve asset does not generate any return in case $P<100 \%$ and no leverage fees apply in case $P>100 \%$. The actual terms of a specific structured product could be different. The risk controlled underlying is merely a calculation agreed between both parties of the derivatives contract.

Substitution of

$$
\frac{d I_{t}}{I_{t}}=P_{t-1} \frac{d S_{t}}{s_{t}}
$$

yields

$$
d I_{t}=I_{t} P_{t-1}(r-q) d t+I_{t} P_{t-1} \sigma_{t} d \varepsilon_{t} .
$$

Equation (6) together with a stochastic volatility model like Heston (1993) or other (see Schoutens, Simons, \& Tistaert, 2004) to model the evolution of $\sigma_{\mathrm{t}}$ produces simulated values for $I_{t}$. To gain additional insight, substitute $P_{t-1}$ by $V / H_{t-1}$ in equation (6) and assume that $\sigma_{t}$ is fairly proxied by $H_{t-1}$. This yields:

$$
d I_{t} \approx I_{t} \frac{V}{H_{t-1}}(r-q) d t+I_{t} V d \varepsilon_{t} .
$$

Equation (7) describes the differential equation of an asset with constant volatility $V$ and a drift term which is copied from the original asset with a correction factor $V / H_{t-1}$. Equation (7) suggests the use of the standard option pricing formula to value basic options such as calls and puts on a risk controlled underlying. The volatility target serves as in input for volatility while the drift of the uncontrolled underlying is multiplied by $V / H_{t-1}$. A practical implementation 
requires an approximation of $H_{0}$. Likely candidates are the historical volatility measure as defined in the derivatives contract or the market volatility implied from options on the uncontrolled underlying.

Continue with the previous example to illustrate. Given the 5 year tenor and the prevailing interest rates there is a total of $7.92 \%$ to spend on options. A first structured product offers $100 \%$ capital protection and $48.44 \%$ participation in the increase of S\&P500. A second structured product now applies a synthetic risk controlled version of S\&P500 as its underlying value. Using equation (7) the structured product provider can fix the volatility target in order to obtain the preferred terms and conditions. The volatility target could for example be set at a level that results in an option premium of exactly $7.92 \%$. With the parameters of our example the resulting volatility target is $9.63 \%$. This volatility target allows to build a 5 year capital protected product with $100 \%$ participation in the increase of the synthetic index.

The example highlights the immediate impact of the volatility target on the option price. Indeed, the risk is controlled but so is the option premium. The risk control mainly benefits the option provider. The risks and costs that come with hedging an option facing a changing market volatility are drastically reduced. The price control mainly benefits the structured product provider, who is able to guide the terms and conditions of the final product.

The final investor should not a priori prefer any of the structured products, assuming all options are fairly priced. Both structured products contain an option component that is initially valued at $7.92 \%$. The alternatives can only be ranked at maturity. Only then will it show whether $48.44 \%$ participation in the S\&P500 out- or underperforms $100 \%$ participation in the risk controlled index. The outcome mainly depends on the comparison between the implied volatility at start date and the realized volatility on maturity date. The implied volatility at start date guides the option price embedded in the first version of the structured product, and fixes the participation in S\&P500 performance. In the second version of the structured product market exposure is time-varying. The resulting participation in actual S\&P500 performance is path dependent and is a function of the volatility target in relation to realized volatility during the product's lifetime. Any preference between both structured products should be based on a view on future realized volatility relative to the current implied volatility.

Risk control is a welcomed technique to face the current low interest rates. At the same time risk control appeals to the growing risk awareness of investors. Both motivations are false. Structured products that apply risk control transfer the volatility risk from the option provider to the end investor. The technique of risk control focusses on volatility and does not claim to increase return per unit of risk. Goldsticker (2012) uses a dataset for S\&P500 starting in the '50s and concludes that such performance hypothesis lacks empirical support. A structured product that applies risk control cannot be considered an upgrade of the uncontrolled version. It is simply a different product, with its own characteristics.

\section{Rules-Based Portfolio Insurance}

The seminal publication of Black \& Jones (1987) sparked a range of dynamic portfolio strategies that prevent a portfolio from falling below a predefined floor level. The technique of Constant Proportion Portfolio Insurance (CPPI hereafter) divides the portfolio allocations in two categories: risky and riskless assets. The risky assets represent the market exposure and are return seekers. The riskless assets evolves in parallel with the floor level that has been set. The probability of breaching the floor should be zero when fully invested in the riskless asset. Money market instruments may serve as the riskless asset if the floor level is defined as a flat line, for example a fixed percentage of initial investment. This will be our working hypothesis.

CPPI states to actively manage the portfolio and rebalance the proportion of risky and riskless assets. Rebalances ensure that the value of the risky assets $(R Y)$ equals a constant proportion $(m)$ of the distance between the portfolio value $(P)$ and the floor level $(F)$ :

$$
R Y=m^{*}(P-F) .
$$

The position in riskless assets $(R L)$ equals $R L=P-R Y$.

The constant proportion or multiplier $m$ lies at the heart of the risk/return balance of any CPPI. The higher $\mathrm{m}$, the more 
the portfolio tolerates risky assets given the distance to the floor $(P-F)$ and vice versa. A higher value for $m$ yields more market exposure but at the same time implies more vulnerability to breach the floor level. In general, a CPPI with a constant proportion $m$ breaches the floor as soon as the risky assets fall by at least $-1 / m$ between two rebalances. To see this, note that the floor is breached if the percentage decrease $d$ of the risky asset consumes the distance to the floor prior to a new rebalance: $-d * R Y=P-F=R Y / m$ which means $d=-1 / m$. This observation has made academics and practitioners think about $m$ as a non-constant multiplier.

Most analyses advocate an inverse relation between the multiplier and the volatility of the risky assets. Zieling, Antje, \& Balder (2014) demonstrate how the return of a CPPI is enhanced if the multiplier is inversely linked to volatility. Intuitively, the cost of CPPI being a convex strategy (Perold \& Sharpe, 1988) is lowered if the "reaction speed" $m$ is modest in more volatile markets. Mantilla-Garcia (2012) equally finds a negative relation between the multiplier and the underlying volatility when looking for the CPPI that optimizes the growth path. Browne (2000) demonstrates a similar relation when optimizing dynamic portfolio strategies against risk-related constraints such as shortfall.

The proposed relation between the multiplier and volatility provides an obvious link with the risk control discussed in the present paper. Assume the following inverse relation between the multiplier $m$ and the volatility $\sigma_{t}$ of the risky assets:

$$
m_{t}=1 / A \sigma_{t} .
$$

Note that equation (9) makes the multiplier time-varying. The constant A does not need to be specified for our discussion. The value for A is likely to be set by the risk department. Recall that the portfolio breaches the floor whenever the risky assets fall by more than $-1 / m$ since the last rebalance. With equation (9) this means that the portfolio can support a fall in the risky assets upto $-A \sigma_{t}$.

A portfolio manager applying $m=1 / A \sigma_{t}$ will rebalance and hold:

$$
R Y=(P-F) /\left(A \sigma_{t}\right) \rightarrow \text { market exposure . }
$$

The remainder of the portfolio is allocated to the riskless asset:

$$
R L=P-(P-F) /\left(A \sigma_{t}\right) \rightarrow \text { cash } .
$$

Now consider a second portfolio manager who equally relates the multiplier inversely to volatility but in addition applies risk control to target the volatility of the risky assets at a level V. At any time, the second manager will equate the value of his risky assets to

$$
R Y=(P-F) /(A V) .
$$

A portion $\left(V / \sigma_{t}\right)$ of the risky assets is exposed to market risk and $\left[1-\left(V / \sigma_{t}\right)\right]$ is invested in cash. The market risk of the second manager ultimately relates to a portion $(P-F) /\left(A \sigma_{t}\right)$ of the total portfolio but differs from what he considers "risky assets". Both managers also hold the same amount of cash at portfolio level, regardless of the actual volatility target $V$. The level of the volatility target impacts the intermediate calculation of what the second manager considers risky and riskless assets but is does not make his portfolio allocation differ from the portfolio of the first manager.

Consider the example where $\sigma=20 \%, V=15 \%, A=1, P=110$ and $F=95$.

The first manager would invest $R Y_{l}=$ market exposure $=(110-95) / 0.20=75$ and $R L_{l}=$ cash $=110-75=35$. The second manager would invest more in "his" risky assets since their volatility is targeted at $15 \%$ which is below the market volatility of $20 \%: R Y_{2}=(110-95) / 0.15=100$. However, the risky assets of the second manager only consist of $0.15 / 0.20=75 \%$ market exposure. To keep volatility as low as $15 \%$ the remaining $25 \%$ of the risky asset is invested in cash. At portfolio level this means: market exposure $=75 \% * R Y_{2}=75$ and cash $=R L_{2}+25 \% * R Y_{2}=10+25=35$. At the top level, both portfolios are allocated identically.

Adding risk control to the risky asset of a CPPI brings the concern for risk mitigation to the front but it does not alter the composition of the portfolio if, for good reasons, the multiplier is already inversely linked to volatility. Note how this confirms in a different way the common knowledge that CPPI is a strategy which transfers volatility risk to the end investor, see Bertrand \& Prigent (2005). 


\section{Manager 1}
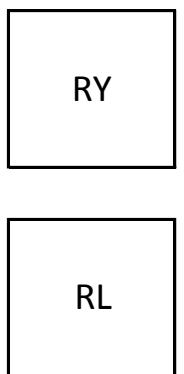
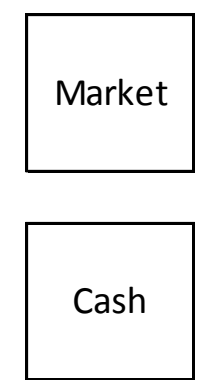

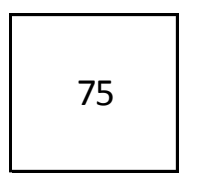

35

Figure 2.Visual representation of two alternative CPPIs.

\section{Conclusion}

Manager 2
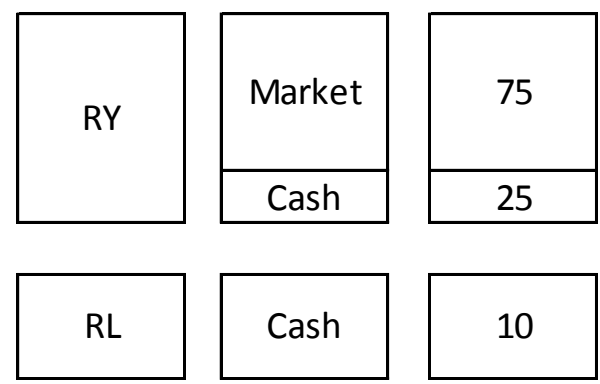

Risk control sets a predefined level of risk the investor is willing to bear and adjusts the portfolio market exposure accordingly. The technique has gained popularity during the financial crisis as both institutional and private investors welcome risk mitigation. The widespread use of risk control is illustrated by the publication of the dedicated Risk Control indices by Standard and Poor's.

Risk control is commonly applied to mainstream financial products. The paper elaborated on the use of risk control to the underlying of structured products. Risk control allows to guide the cost of the embedded option at initiation and makes the terms more commercially viable. For example when the participation level of a classic version is low due to low interest rates or high implied volatilities. However, the argument of low interest rates was shown to be false. The appraisal of a risk controlled structured product calls for a view on future realized volatility as it transfers volatility risk to the end investor.

Risk control can equally apply to the risky asset of rules-based portfolio insurance products. Again risk control can help to address the growing concern for risk mitigation but it does not alter the composition of the portfolio. CPPI transfers volatility risk to the end investor even without the application of risk control.

\section{References}

Bertrand, P., \&J.-L. Prigent (2005). Portfolio insurance strategies: OBPI versus CPPI. Finance, 26, 5-32.

Black, F., \& Jones, R. (1987). Simplifying portfolio insurance. The Journal of Portfolio Management (Fall), 48-51. http://dx.doi.org/10.3905/jpm.1987.409131

Black, F., \& Scholes, M.(1973). The pricing of options and corporate liabilities. Journal of Political Economy, 81(3), 637-654.

Browne, S. (2000). Risk-constrained dynamic active portfolio management. Management Science, 46(9), 1188-1199. http://dx.doi.org/10.1287/mnsc.46.9.1188.12233

Goldsticker, R. (2012). Volatility targeting may miss the mark. BNY Mellon Asset Management White Paper.

Heston, S. (1993). A closed-form solution for options with stochastic volatility with applications to bond and currency options. Review of Financial Studies, 6(2), 327-343. http://dx.doi.org/10.1093/rfs/6.2.327

Hull, J. (1989). Options, Futures, and Other Derivatives, Prentice Hall

Mantilla-Garcia, D. (2012). Growth optimal portfolio insurance and the benefits of high correlation. Koris International working paper.

Perold, A., \& Sharpe, W. (1988). Dynamic strategies for asset allocation. Financial Analysts Journal, 16-27. http://dx.doi.org/10.2469/faj.v51.n1.1871

Schoutens, W., Simons, E., \& Tistaert, J. (2004). A perfect calibration! Now what? Wilmott Magazine, 66-78.

Standard And Poor's. (2015). Index Mathematics Methodology.

Zieling, D., Antje, M., \& Balder, S. (2014). Performance evaluation of optimized portfolio insurance strategies. Journal of Banking and Finance, 43, 212-225. http://dx.doi.org/10.1016/j.jbankfin.2014.03.027

\section{$(\mathrm{cc}) \overline{\mathrm{E} Y}$}

This work is licensed under a Creative Commons Attribution 3.0 License. 